\title{
Impact of Antibiotic Resistance on Chemotherapy for Pneumococcal Infections
}

\author{
ROMAN PALLARES, PEDRO F. VILADRICH, JOSEFINA LIÑARES, CARMEN CABELLOS, \\ and FRANCESC GUDIOL
}

\begin{abstract}
Over the past three decades, penicillin-resistant pneumococci have emerged worldwide. In addition, penicillinresistant strains have also decreased susceptibility to other $\beta$-lactams (including cephalosporins) and these strains are often resistant to other antibiotic groups, making the treatment options inuch more difficult. Nevertheless, the present in vitro defimitions of resistance to penicillin and cephalosporins in pneumococci could not be appropriated for all types of pneumococcal infections. Thus, current levels of resistance to penicillin and cephalosporin seem to have little, if any, clinical relevance in nonmeningeal infections (e.g., pneumonia or bacteremia). On the contrary, numerous clinical failures have been reported in patients with pneunococcal meningitis caused by strains with MICs $\geq 0.12 \mu \mathrm{g} / \mathrm{ml}$, and penicillin should never be used in pneumococcal meningitis except when the strain is known to be fully susceptible to this drug. Today, therapy for pneumococcal neningitis should mainly be selected on the basis of susceptibility to cephalosporins, and most patients nuay currently be treated with high-dose cefotaxime $( \pm)$ vanconycin, depending on the levels of resistance in the patient's geographic area. In this review, we present a practical approach, based on current levels of antibiotic resistance, for treating the most prevalent pneumococcal infections. However, it should be emphasized that the most appropriate antibiotic therapy for infections caused by resistant pneumococci remains controversial, and comparative, randomized studies are urgently needed to clarify the best antibiotic therapy for these infections.
\end{abstract}

\section{INTRODUCTION}

$\mathbf{P}$ NEUMOCOCCAL INFECTIONS are very prevalent worldwide, and Streptococcus pneumoniae is a major cause of pneumonia, meningitis, acute otitis media, and acute sinusitis. ${ }^{10,70}$ During the past 30 years, pneumococci have developed resistance to several antimicrobial agents, including tetracycline, penicillin, trimethoprim-sulfamethoxazole, chloramphenicol, erythromycin, cephalosporins, and other drugs. 5,12,17,29,54,61 But, in terms of therapy, the real problem has been the development of resistance to penicillin. This is because penicillin was the time-honored treatment for pneumococcal infections for decades, and alternative drugs were only necessary in penicillin-allergic patients.

An interesting issue is that, shortly after the introduction of penicillin in 1940 , the first strain of $S$. pneumoniae with decreased susceptibility to penicillin was produced in the laboratory, ${ }^{28}$ but the first clinical isolate did not appear until more than 20 years later in Boston. ${ }^{52}$ In the late 1960 s, pneumococcal strains with moderate penicillin resistance were isolated in Australia and New Guinea. ${ }^{41,42}$ In the 1970s, an epidemic of high-level penicillin- and multidrug-resistant pneumococci was detected in pediatric wards in South Africa. ${ }^{6,50}$ Subsequently, resistant strains were identified in Europe, particularly in Spain. ${ }^{30,57,60}$ Finally, in the 1980 s, penicillin-resistant pneumococci emerged in many countries. Today, the prevalence of pneumococci resistant to penicillin and other antibiotics is increasing worldwide. ${ }^{14,20,21,37,39,45,65,66}$

As shown in several studies, resistance rates varied with the geographic area and age of the patient, the highest being the rate of resistance among isolates from otitis media in children. $21,54,60,61$ It is important to emphasize that antimicrobial consumption is a major factor contributing to penicillin resistance and other antibiotic resistance in pneumococci. ${ }^{7,13}$

Although antibiotic resistance is a complex phenomenon that we do not know very well, it is important to note that resistant 
pneumococcal strains have the ability to spread rapidly throughout the world. For example, the Spanish clone $23 \mathrm{~F}$ and $6 \mathrm{~B}$ have been disseminated to other countries in Europe and to other continents. ${ }^{69,82}$

The mechanism of resistance of pneumococci to penicillin is due to alterations of the penicillin binding proteins (PBPs) that have reduced their affinity for penicillin and related $\beta$-lactams. ${ }^{48,64,85,86}$ Therefore, susceptibility to other $\beta$-lactams is also affected and the minimal inhibitory concentrations (MICs) of these drugs rise in parallel with those of penicillin $\mathrm{G}$, although with different degrees depending on the drug $59,67,76,83$ (Table 1). Cefotaxime, ceftriaxone, cefpirome, and cefepime are the parenteral cephalosporins that yield the lowest MICs against penicillin-resistant strains. The MICs of carbapenems are smaller than those of cephalosporins. Thus, imipenem is highly active against penicillin-resistant strains, but meropenem is slightly less active in vitro than imipenem. Amongst oral $\beta$ lactams, amoxicillin yields the lowest MICs against penicillinresistant pneumococci, and cefuroxime and cefpodoxime are the oral cephalosporins that yield the lowest MICs, although these are several times higher than those of amoxicillin. In addition, penicillin-resistant strains are more likely to be resistant to other antibiotic groups such as erythromycin, tetracycline, chloramphenicol, and trimethoprim-sulfamethoxazole. ${ }^{17,54,61}$ However, the newest quinolones (e.g., trovafloxacin, sparfloxacin, grepafloxacin) seem to be very active compounds against penicillin-resistant and -susceptible strains.

The current in vitro definition of penicillin resistance by $S$. pneumoniae (National Committee for Clinical Laboratory Standards, NCCLS 1995) is as follows: susceptible strains (MIC $\leq$ $0.06 \mu \mathrm{g} / \mathrm{ml}$ of penicillin $\mathrm{G}$ ), intermediate resistance (MIC $0.12-1.0 \mu \mathrm{g} / \mathrm{ml}$ of penicillin $\mathrm{G}$ ), and high-level resistance (MIC $\geq 2.0 \mu \mathrm{g} / \mathrm{ml}$ of penicillin $\mathrm{G}$ ). However, the laboratory definition of resistance to penicillin was established before the clinical relevance of this level of resistance had been determined. In other words, the current in vitro definitions of peni-

Table 1. IN Vitro Activity of Several Antibiotics in 952 Penicillin-Resistant StreptococCus PNEUMoniaE ${ }^{\mathrm{a}}$

\begin{tabular}{lcc}
\hline Antibiotic & MIC range & MIC-50/MIC-90 \\
\hline Penicillin & $0.12-4$ & $1 / 2$ \\
Amoxicillin & $0.06-4$ & $0.5 / 1$ \\
Cefuroxime & $1-16$ & $2 / 8$ \\
Cefaclor & $0.5-64$ & $32 / 64$ \\
Cefixime & $2-64$ & $8 / 32$ \\
Cefotaxime & $0.03-4$ & $0.5 / 1$ \\
Ceftriaxone & $0.03-4$ & $0.5 / 1$ \\
Cefpirome & $0.03-2$ & $0.25 / 0.5$ \\
Ceftazidime & $1-64$ & $16 / 64$ \\
Imipenem & $0.03-1$ & $0.06 / 0.25$ \\
Meropenem & $0.03-2$ & $0.12 / 0.5$ \\
Erythromycin & $0.03->128$ & $0.12 / 128$ \\
Tetracycline & $0.03->128$ & $16 / 64$ \\
Cotrimoxazole & $0.12-16$ & $4 / 8$ \\
Chloramphenicol & $0.25-64$ & $4 / 16$ \\
Vancomycin & $0.12-1$ & $0.25 / 0.5$ \\
\hline
\end{tabular}

aData from the Microbiology Laboratory (1990-1995), Bellvitge Hospital, Barcelona.

${ }^{b}$ The ratio of trimethoprim-sulfamethoxazole is $1 / 19$. cillin resistance are open to question, particularly for those pneumococcal strains causing nonmeningeal infections.

Although no prospective, randomized studies on the therapy of resistant pneumococcal infections have been carried out, the published data suggest that moderate penicillin-resistant pneumococci causing nonmeningeal infections such as pneumonia or bacteremia have no therapeutic significance. $11,31,33,55,74,75,80,84,91$ This is because the serum concentrations achieved with penicillin or related $\beta$-lactams are several times higher than the MICs of the strains. ${ }^{4}$ On the other hand, however, pneumococcal meningitis poses a special therapeutic problem because of the levels of penicillin achieved in the cerebrospinal fluid (CSF) are inadequate to kill penicillin-resistant pneumococci including those with intermediate resistance, ${ }^{43}$ and several clinical failures have been reported. . $^{19,34,36,78}$

The management of pneumococcal infections caused by resistant strains has been debated in recent reviews, ${ }^{19,34,36,61,78}$ but several important questions remain to be answered. The most important considerations in selecting empirical antibiotic therapy in patients with a suspected pneumococcal infection are the following: prevalence and patterns of resistance in the patient's geographic area; site of infection (e.g., meningitis); risk factors for penicillin-resistant strains (e.g., prior antibiotic use, young age, day-care attendance, prior hospitalization, nosocomial infection) ${ }^{16,63,73,74}$; severity of illness and probability of death; route of drug administration; and potential toxicity and costs.

In this review, we will discuss the treatment of the most prevalent pneumococcal infections, focusing principally on adult patients. The regimens proposed herein are based on the current levels of resistance, but these recommendations may change in the near future.

\section{THERAPY FOR PNEUMONIA}

There are several reports dealing with the response to $\beta$-lactam antibiotic therapy in penicillin-resistant pneumococcal pneumonia or bacteremia. ${ }^{11,31,33,55,74,75,80,84,91}$

Friedland and Klugman ${ }^{33}$ carried out a prospective study of community-acquired pneumococcal infections in 207 South African children, most of them were treated with penicillin or ampicillin at a standard dosage. They found that the mortality rate was $14 \%$ in children with penicillin-resistant pneumococcal infections and $11 \%$ in children with penicillin-susceptible infection.

Tan and colleagues ${ }^{84}$ reported their experience during a 3year period in Houston. All but 1 of 19 children with systemic infections caused by intermediate penicillin-resistant pneumococci responded adequately to initial $\beta$-lactam therapy (mostly amoxicillin or cefuroxime).

Friedland ${ }^{31}$ reported a series of 108 children with bacteremic pneumococcal infections, excluding meningitis. In children with pneumonia who were treated with ampicillin or an equivalent $\beta$-lactam agent, $88 \%$ with penicillin-resistant infections and $93 \%$ with penicillin-susceptible infections had improved by day 7 of therapy.

Recently, we conducted a prospective nonintervention study with 504 adult patients with severe pneumococcal pneumonia; $29 \%$ of them were infected with penicillin-resistant strains. ${ }^{75}$ Although the mortality rate was significantly higher in penicillin-resistant than in penicillin-susceptible cases (38\% vs. 
$24 \%$ ), after adjustment for other variables, the odds ratio for mortality in patients with penicillin-resistant strains was not statistically significant. Moreover, when we compared the mortality rate in patients treated with penicillin or ampicillin, there were no statistically significant differences between patients infected with penicillin-resistant and those infected with penicillin-susceptible strains. Likewise, among patients treated with cefotaxime or ceftriaxone, the mortality rate was not significantly different in those infected with cephalosporin-resistant strains when compared with those infected with cephalosporinsusceptible strains. Our conclusion was that current levels of resistance to penicillin and cephalosporins are not associated with increased mortality in patients with severe pneumococcal pneumonia. Thus, these antibiotics can still be used as the therapy of choice for this disease. ${ }^{75}$

We suggest the following antibiotic therapy for communityacquired pneumococcal pneumonia (Table 2).

\section{Initial empirical therapy}

This refers to the treatment for a patient with a clinical picture and radiologic findings highly suggestive of pneumococcal pneumonia before the culture results are known. It should be emphasized that in patients with clinical suspicion of pneumococcal pneumonia, the diagnosis may be strongly reinforced by demonstrating polymorphonuclear leukocytes (PMNs) and Gram-positive cocci in pairs in the sputum. ${ }^{71}$ However, sometimes the clinical picture is not clear enough and the infection may be caused by other pathogens. This possibility should be taken into account in selecting empirical therapy, particularly when the patient has severe pneumonia. Empirical therapy for pneumococcal pneumonia should be classified according to the severity of the infection (Table 2).

Mild-to-moderate pneumonia. Mild-to-moderate pneumonia should be considered in a patient who is less than 65 years old and has no co-morbid conditions; in these cases, an outpatient treatment can be prescribed.

Amoxicillin may be the therapy of choice for patients with $\mathrm{mild} /$ moderate pneumonia in whom a characteristic clinical picture of pneumococcal pneumonia is present. However, amoxicillin-clavulanate may be preferred in some patients such as those with chronic obstructive pulmonary disease (COPD) in whom the causative organisms may be $S$. pneumoniae or other common pathogens such as Haemophilus influenzae (often $\beta$ lactamase positive).

Alternative drugs such as cefuroxime, erythromycin, or penicillin procaine should be selected according to the history of allergy or when the oral route is not well tolerated.

In patients in whom, after a careful clinical evaluation, his/her physician has doubts about the diagnosis of pneumococcal pneumonia versus atypical pneumonia, a macrolide (e.g., erythromycin) should be given. However, it is important to know that if the causative organisms is a pneumococcus resistant to erythromycin the patient may not respond to this therapy. ${ }^{68}$

Severe pneumonia. Patients with severe community-acquired pneumonia should be hospitalized, and the criteria for severe pneumonia includes (one or more): age $\geq 65$ years; serious underlying conditions (e.g., COPD, diabetes, malignancies, heart failure, chronic renal failure, splenectomy, cirrhosis, or chronic
Table 2. Suggested Antibiotic Regimens FOR PNEUMOCOCCAL PNEUMONIA

1. Initial empirical therapy

Mild/moderate pneumonia

Primary Oral amoxicillin $1 \mathrm{~g} / 8$ hour or oral amoxicillin-clauvulanate $1 \mathrm{~g} / 8 \mathrm{hr}$

Alternative Oral cefuroxime $750 \mathrm{mg} / 8-12$ hour or oral erythromycin $500 \mathrm{mg} / 6 \mathrm{hr}$ or i.m. penicillin procaine $1.2 \mathrm{mU} / 12 \mathrm{hr}$

Severe pneumonia

Primary i.v. ceftriaxone $1-2 \mathrm{~g} / 24 \mathrm{hr}$ or i.v. cefotaxime 1-2 $\mathrm{g} / 8 \mathrm{hr}$ or i.v. amoxicillin-clavulanate $2 \mathrm{~g} / 8 \mathrm{hr}(+/-)$ i.v. erythromycin $1 \mathrm{~g} / 6 \mathrm{hr}$

Alternative i.v. cefpirome $1-2 \mathrm{~g} / 12 \mathrm{hr}$ or i.v. cefepime 1-2 g/8-12 hr or i.v. imipenem $500 \mathrm{mg} /$ $6 \mathrm{hr}$ or i.v. meropenem $1 \mathrm{~g} / 8 \mathrm{hr}$ or i.v. vancomycin $1 \mathrm{~g} / 12 \mathrm{hr}(+/-)$ i.v. erythromycin $1 \mathrm{~g} / 6 \mathrm{hr}$ or a new quinoline

2. Therapy when in vitro studies are known (severe pneumonia) Susceptible strains to penicillin (MICs $\leq 0.06 \mu \mathrm{g} / \mathrm{ml}$ )

Primary i.v. penicillin $\mathrm{G} 1 \mathrm{mU} / 4 \mathrm{hr}$ or i.v. ampicillin $1 \mathrm{~g} / 6 \mathrm{hr}$

Alternative i.v. cefuroxime $1.5 \mathrm{~g} / 8 \mathrm{hr}$ or i.v. ceftriaxone $1 \mathrm{~g} / 24 \mathrm{hr}$ or i.v. cefotaxime $1 \mathrm{~g} / 8 \mathrm{hr}$ or i.v. erythromycin $1 \mathrm{~g} / 6 \mathrm{hr}$

Strains with decreased susceptibility to penicillin penicillin MICs 0.12 to $2.0 \mu \mathrm{g} / \mathrm{ml}$

Primary i.v. penicillin G $2 \mathrm{mU} / 4 \mathrm{hr}$ or i.v. ampicillin $2 \mathrm{~g} / 6 \mathrm{hr}$

Alternative i.v. ceftriaxone $1-2 \mathrm{~g} / 24 \mathrm{hr}$ or i.v. cefotaxime $1-2 \mathrm{~g} / 8 \mathrm{hr}$ or i.v. erythromycin $1 \mathrm{~g} / 6 \mathrm{hr}$

Penicillin MICs $\geq 4.0 \mu \mathrm{g} / \mathrm{ml}$

Primary Continue with the initial empirical therapy if the clinical response is satisfactory

Alternative i.v. imipenem $500 \mathrm{mg} / 6 \mathrm{hr}$ or i.v. meropenem $1 \mathrm{~g} / 8 \mathrm{hr}$ or i.v. erythromycin $\mathrm{lg} / 6 \mathrm{hr}$ or i.v. vancomycin $1 \mathrm{~g} / 12 \mathrm{hr}$ or a new quinoline

i.m., Intramuscular; i.v., intravenous; MICs, minimal inhibitory concentrations.

Dosage recommendations are approximate values for an adult patient of $60-70 \mathrm{~kg}$.

Dosage and intervals can be different in infants and children and should be calculated according to their age and specific conditions. In addition, pediatric patients may have pathogens causing pneumonia different than those in adults and thus it should be considered in selecting empirical antibiotic therapy.

Primary therapy is the treatment of choice suggested.

Alternative therapy should be selected according to (i) the patterns of antibiotic resistance in the patient's geographic area or when the culture results are known should be based on the in vitro susceptibility studies; (ii) history of allergy; (iii) toxicity; and (iv) costs.

alcoholism); previous pneumonia $<1$ year ago; altered mental status; respiration rate $>30 / \mathrm{min}$; blood pressure $<90 / 60$; temperature $>101^{\circ} \mathrm{F}$; WBC $<4000$ or $>30,000 / \mathrm{mm}^{3} ; \mathrm{PaO}_{2}<60$ mmHg $\left(<90 \% \mathrm{O}_{2}\right.$ saturation); $\mathrm{PaCO}_{2}>50$; needs mechanical ventilation; chest X-ray $>1$ lobe; pleural effusion; Hct $<30$; sepsis; and extrapulmonary disease (e.g., meningitis). One im- 
portant clinical consideration is that in a patient with severe pneumococcal pneumonia, the possibility of having associated meningitis should be evaluated carefully because the treatment options are substantially different (see treatment of meningitis).

To treat pneumococci and other common bacteria (e.g., $H$. influenzae or other Gram-negative bacilli), the initial empirical therapy for severe pneumonia should include an appropriate cephalosporin or amoxicillin-clavulanate (Table 2). Additionally, erythromycin should be added in cases in which Legionella or another atypical pathogen cannot reasonably be ruled out.

In patients with severe underlying diseases (e.g., neutropenic patients) in whom some fastidious organisms such as Pseudomonas also needs to be treated, the combination of cefpirome or cefepime or imipenem or meropenem with erythromycin should be considered. It is important to know that ceftazidime has little activity against penicillin-resistant pneumococci (Table 1).

There is little experience in treating patients with pneumococcal pneumonia with vancomycin alone and this drug has no activity against other pathogens such as Gram-negative bacilli. Thus, when vancomycin is selected for empirical therapy of severe pneumonia (e.g., allergy to $\beta$-lactams or in places in which a very high level cephalosporin resistance has been detected) a combination with other drugs (e.g., aztreonam or ciprofloxacin) should be considered. Serum vancomycin levels should be monitored in these patients. In our opinion, and based on the current levels of antibiotic-resistant pneumococci, vancomycin should not be widely used for treating pneumonia.

The newest quinolones (e.g., trovafloxacin, sparfloxacin, grepafloxacin) may play an important role in the empirical treatment of severe pneumonia cases in the near future.

\section{Therapy for known pneumococcal pneumonia}

When culture results (e.g., positive cultures from blood, pleural fluid, or a lower respiratory tract specimen) and in vitro studies are known, any change in antibiotic therapy should be based on the results of susceptibility tests and on the light of clinical evolution of the patient.

Penicillin or ampicillin (at standard dosage) remains the therapy of choice for susceptible strains. Alternative drugs (see Table 2) may be necessary in penicillin-allergic patients.

Patients infected with strains having penicillin MICs of $0.12-2.0 \mu \mathrm{g} / \mathrm{ml}$ may respond to penicillin or ampicillin therapy, although the administration of high dose (for example, $150,000-200,000 \mathrm{U} / \mathrm{kg}$ per day of penicillin G) would be prudent to achieve higher serum and pulmonary levels of the drug.

It is not well known whether patients infected with strains for which penicillin MIC $\geq 4 \mu \mathrm{g} / \mathrm{ml}$ could respond to intravenous (i.v.) penicillin therapy. In these patients, consecutive therapy should be based on the response to the initial empirical therapy and the results of the in vitro studies. In the case that the patient is doing well with a cephalosporin or amoxicillin-clavulanate, this therapy should be continued. On the contrary, if the clinical response is not satisfactory, other drugs such as imipenem, meropenem, erythromycin, vancomycin, or a new quinoline should be considered according to the results of the in vitro studies.

\section{THERAPY FOR MENINGITIS}

Response to therapy in penicillin-resistant and cephalosporin-resistant pneumococcal meningitis is different to that in nonmeningeal infections. We believe that clinicians should have in mind some important considerations when selecting antibiotic therapy for pneumococcal meningitis:

(i) There have been numerous case reports of failure of penicillin therapy in patients with pneumococcal meningitis caused by intermediate or high-level penicillin-resistant strains. 1,6,22,24,27,38,46,47,62,72,77,79,92 Thus, because penicillin-resistant strains are spread worldwide, the initial therapy for pneumococcal meningitis should not be penicillin or ampicillin.

(ii) Several patients with pneumococcal meningitis infected with strains showing decreased susceptibility to cephalosporins failed cefotaxime or ceftriaxone treatment. ${ }^{3,8,9,18,23,51,53,58,81}$ In most of them, cefotaxime or ceftriaxone were administered at the standard dosage for meningitis. However, some experience in adults suggests that the administration of a higher dosage of cefotaxime may be effective for treating patients with cephalosporin-resistant pneumococcal meningitis, at least for those with intermediate resistance. . $^{2,88,90}$

(iii) Vancomycin could be a good alternative for pneumococcal meningitis caused by penicillin- and cephalosporin-resistant strains. Nevertheless, the administration of vancomycin at $30 \mathrm{mg} / \mathrm{kg}$ per day (the dosage recommended for adult patients) was associated with several failures in adult pneumococcal meningitis. ${ }^{89}$ These failures could be due to the highly variable concentrations of vancomycin achieved in the CSF, especially when dexamethasone was given concomitantly. However, we are unaware of any reported vancomycin failure in pneumococcal meningitis in pediatric patients in whom vancomycin is administered at higher dosages $(60 \mathrm{mg} / \mathrm{kg}$ per day). ${ }^{56}$

(iv) In penicillin-resistant pneumococcal meningitis, chloramphenicol treatment may not be appropriated. Several penicillin-resistant pneumococci are also resistant to chloramphenicol. In addition, unsatisfactory results with chloramphenicol (despite the strains that were susceptible to this drug based on the MICs) in penicillin-resistant pneumococcal meningitis have been reported. ${ }^{32}$ These failures could be due to a poor bactericidal activity of chloramphenicol in such strains. ${ }^{32}$

We suggest the following antibiotic therapy for pneumococcal meningitis (Table 3 ).

\section{Initial empirical therapy}

This terminology refers to the initial treatment for a patient with pneumococcal meningitis (a purulent meningitis and a CSF Gram stain showing typical Gram-positive diplococci). However, in cases with purulent meningitis and a CSF Gram stain showing no microorganisms, several possible pathogens should be considered in selecting the initial therapy, depending on the clinical suspicion in each case.

In our opinion, the initial empirical therapy for pneumococcal meningitis should be a cephalosporin such as cefotaxime. However, because some strains may have decreased susceptibility to these drugs, it may be prudent to suggest high-dose cefotaxime for the initial therapy. Other cephalosporins such as 
Table 3. Suggested Antibiotic Regimens FOR PNEUMOCOCCAL MENINGITIS

1. Initial empirical therapy

Primary i.v. cefotaxime $300-400 \mathrm{mg} / \mathrm{kg}$ per day $(5-6 \mathrm{~g} /$ $6 \mathrm{hr}$ ) (maximum $24 \mathrm{~g} /$ day) $(+/-)$ i.v. vancomycin $30 \mathrm{mg} / \mathrm{kg}$ per day $(1 \mathrm{~g} / 12 \mathrm{hr}$ ) (in children $60 \mathrm{mg} / \mathrm{kg}$ per day)

Alternative i.v. vancomycin $(+/-)$ i.v. rifampin 900 $\mathrm{mg} / 24 \mathrm{hr}$ or i.v. cefotaxime $(+)$ i.v. rifampin

2. Therapy when in vitro studies are known

Strains susceptible to penicillin (MICs $\leq 0.06 \mu \mathrm{g} / \mathrm{ml}$ )

Primary i.v. penicillin $\mathrm{G} 3-4 \mathrm{mU} / 4 \mathrm{hr}$

Alternative i.v. cefotaxime $3-4 \mathrm{~g} / 6 \mathrm{hr}$ or i.v. ceftriaxone $4 \mathrm{~g} / 24 \mathrm{hr}$ or i.v. vancomycin $(+/-)$ i.v. rifampin or i.v. chloramphenicol $1 \mathrm{~g} / 6 \mathrm{hr}$

Strains with decreased susceptibility to penicillin penicillin MICs $\geq 0.12 \mu \mathrm{g} / \mathrm{ml}$

Cefotaxime MICs $\leq 0.25 \mu \mathrm{g} / \mathrm{ml}$

Primary i.v. cefotaxime $3-4 \mathrm{~g} / 6 \mathrm{hr}$ or i.v. ceftriaxone $4 \mathrm{~g} / 24 \mathrm{hr}$

Alternative i.v. vancomycin $(+/-)$ i.v. rifampin

Cefotaxime MICs 0.5 to $1.0 \mu \mathrm{g} / \mathrm{ml}$

Primary i.v. cefotaxime $300-400 \mathrm{mg} / \mathrm{kg}$ per day (5-6 g/6 hr) (maximum $24 \mathrm{~g} /$ day)

Alternative i.v. vancomycin $(+/-)$ i.v. rifampin

Cefotaxime MICs $\geq 2.0 \mu \mathrm{g} / \mathrm{ml}$

Primary i.v. cefotaxime $300-400 \mathrm{mg} / \mathrm{kg}$ per day (5-6 $\mathrm{g} / 6 \mathrm{hr})(+/-)$ i.v. vancomycin $30 \mathrm{mg} / \mathrm{kg}$ per day $(1 \mathrm{~g} / 12 \mathrm{hr}$ ) (in children $60 \mathrm{mg} / \mathrm{kg}$ per day)

Alternative i.v. vancomycin $(+/-)$ i.v. rifampin (or intrathecal vancomycin $5-20 \mathrm{mg} / 24-48 \mathrm{hr}$ ) or i.v. meropenem $2 \mathrm{~g} / 8 \mathrm{hr}$ or i.v. imipenem $1 \mathrm{~g} / 6 \mathrm{hr}$ or i.v. chloramphenicol $1 \mathrm{~g} / 6 \mathrm{hr}$

i.v., intravenous; MICs, minimal inhibitory concentrations; MBCs, minimal bactericidal concentrations.

These suggested antibiotic regimens are for treating patients with pneumococcal meningitis in regions in which penicillinresistant pneumococci are reported.

Dosage recommendations are approximate values for an adult patient of $60-70 \mathrm{~kg}$.

Dosage and intervals can be different in infants and children, and should be calculated according to their age and specific conditions. In addition, pediatric patients may have pathogens causing meningitis different from those in adults and thus it should be considered in selecting empirical antibiotic therapy, particularly in cases of purulent meningitis with no microorganisms in the CSF Gram stain.

Primary therapy is the treatment of choice suggested.

Alternative therapy should be selected according to (i) the patterns of antibiotic resistance in the patient's geographic area or when the culture results are known should be based on the in vitro susceptibility studies; (ii) the pharmacokinetics of the drugs; (iii) history of allergy; (iv) toxicity; and (v) costs. cefpirome appear to be promising for resistant pneumococcal meningitis.

In places where high-level cephalosporin resistance (MICs of cefotaxime $\geq 2 \mu \mathrm{g} / \mathrm{ml}$ ) has been detected, cefotaxime may be administered in combination with vancomycin. However, it is important to have in mind some considerations regarding this combination: (i) some studies of animals with cephalosporinresistant meningitis have suggested that the combination of cephalosporin and vancomycin is more effective than either drug alone, ${ }^{35}$ however, to our knowledge little clinical experience with this combination has been published ${ }^{56}$; (ii) even if the combination is given, in adult patients cefotaxime should be administered at a high-dosage regimen because vancomycin (at the recommended dosage) may achieve insufficient CSF levels $^{89}$; (iii) by contrast, in children in whom vancomycin may be administered at higher dose and this drug alone may be effective for pneumococcal meningitis, the concomitant administration of high-dose cefotaxime might be less important than in adults, and the standard dose of cefotaxime or ceftriaxone might be enough; (iv) vancomycin should be discontinued when in vitro studies are known and the pneumococcus is susceptible to penicillin or cephalosporins.

An alternative regimen for the empirical therapy may be vancomycin with or without rifampin. Vancomycin alone may be appropriate for pediatric patients. However, in adults the combination of vancomycin and rifampin may be more appropriate (see comments on vancomycin dosage and levels above).

The combination of cefotaxime or ceftriaxone and rifampin appeared to be promising. However, some in vitro studies in the laboratory have shown an antagonistic effect between rifampin and $\beta$-lactams, although this has not been confirmed in animal studies. ${ }^{87}$ To date, the relevance of this phenomenon in clinical practice is not well known, although some data in children with meningitis have suggested that this combination may enhance CSF bactericidal activity compared with that of cef-

Table 4. Suggested Antibiotic Regimens FOR OTITIS MEDIA AND SINUSITIS

Primary Oral amoxicillin $50-80 \mathrm{mg} / \mathrm{kg}$ per day $(\mathrm{l} \mathrm{g} / 6$ $8 \mathrm{hr}$ ) or oral amoxicillin-clavulanate $1 \mathrm{~g} / 8 \mathrm{hr}$

Alternative Oral cefuroxime $750 \mathrm{mg} / 8-12 \mathrm{hr}$ or i.m. ceftriaxone $1 \mathrm{~g} / 24 \mathrm{hr}$ or oral erythromycin $500 \mathrm{mg} / 6 \mathrm{hr}$ or oral clarithromycin 500 $\mathrm{mg} / 12 \mathrm{hr}$ or oral azithromycin $1 \mathrm{~g} / 24 \mathrm{hr}$ or oral TMP-SMZ 160/800 mg/12 hr

i.m., Intramuscular; TMP-SMZ, trimethoprim-sulfamethoxazole.

Dosage recommendations are approximate values for adult patients. Doses/intervals in parenthesis are those recommended for an adult patient of $60-70 \mathrm{~kg}$.

Dosage and intervals can be different in infants and children, and should be calculated according to their age and specific conditions.

Primary therapy is the treatment of choice suggested.

Alternative therapy should be selected according to (i) the patterns of antibiotic resistance in the patient's geographic area or if the culture results are known should be based on the in vitro susceptibility studies; (ii) history of allergy; (iii) toxicity; and (iv) costs. 
triaxone alone. ${ }^{56}$ Rifampin cannot be used as monotherapy because of the rapid development of resistance.

\section{Therapy for known pneumococcal meningitis}

When culture results (positive CSF and/or blood cultures) and in vitro studies are known, any change in antibiotic therapy should be based on the results of susceptibility tests and on the light of clinical evolution of the patient. A control lumbar puncture should be performed 24-36 hr after the start of antibiotic therapy in all patients with resistant pneumococcal meningitis.

Penicillin remains the therapy of choice for susceptible strains, and alternative drugs are only necessary in penicillin allergic patients.

Patients infected with strains with decreased susceptibility to penicillin (MICs $\geq 0.12 \mu \mathrm{g} / \mathrm{ml}$ ) should not be treated with penicillin. In such cases, cefotaxime or ceftriaxone, using the standard dose for meningitis, may be the therapy of choice for those with MICs of cefotaxime $\leq 0.25 \mu \mathrm{g} / \mathrm{ml}$.

Based on the concept that to kill a pathogen the antibiotic concentration in CSF should exceed by 8 - to 10 -fold the minimal bactericidal concentration (MBC) of the drug, it may be prudent to suggest high-dose cefotaxime for those cases with MICs of cefotaxime $0.5-1.0 \mu \mathrm{g} / \mathrm{ml}$. This is because the cefotaxime MBC may be one dilution higher than the cefotaxime MIC, and clinical failures have been reported in patients infected with strains having cefotaxime MICs as small as 0.5 $\mu \mathrm{g} / \mathrm{ml}$ who were treated with standard dose of cefotaxime or ceftriaxone. ${ }^{3,8,9,18,23,51,53,58,81}$ Ceftriaxone administered at a dose higher than $4 \mathrm{~g} /$ day is not recommended because of potential side effects (e.g., biliary stones). To date, there is no experience with other drugs such as cefpirome or cefepime.

Up to now, several failures have been reported in cephalosporin-resistant pneumococcal meningitis (MICs of cefotaxime $\geq 2 \mu \mathrm{g} / \mathrm{ml}$ ) using standard dose of cefotaxime or ceftriaxone ${ }^{88}$ However, there are some reported cases with MICs of cefotaxime of $2 \mu \mathrm{g} / \mathrm{ml}$ that were cured with high-dose cefotaxime. ${ }^{2,88,90}$ In cases in which the pneumococcus has an MIC of cefotaxime $\geq 2 \mu \mathrm{g} / \mathrm{ml}$ and the patient is doing well with the initial empirical therapy (e.g., high-dose cefotaxime with or without vancomycin), this therapy should be continued. On the other hand, if the patient has no good clinical response, an alternative therapy should be considered in the light of the results of a second lumbar puncture. These regimens may include vancomycin with or without rifampin (or intrathecal vancomycin) or alternatively meropenem or imipenem or chloramphenicol (based on in vitro studies), or perhaps new compounds (e.g., clinafloxacin).

The MICs of meropenem may be smaller than those of cefotaxime in cephalosporin-resistant strains, but the doses recommended and the CSF levels achieved appear not to be very promising. ${ }^{25}$ Although imipenem may have MICs smaller than those of meropenem and some patients with meningitis have been cured with this drug, the potential risk of seizures should be taken into account. In addition, meropenem and imipenem may produce hypersensitivity reactions in $\beta$ lactam-allergic patients. In the case that chloramphenicol is selected as an alternative therapy, MBCs determinations should be performed. ${ }^{32}$

\section{THERAPY FOR OTITIS MEDIA AND SINUSITIS}

Acute otitis media and acute sinusitis are most commonly caused by $S$. pneumoniae, $H$. influenzae, or Moraxella catarrhalis. ${ }^{15,26,40,44,49}$ In acute otitis media, response to antibiotic therapy is often difficult to interpret due to a high rate of spontaneous resolution. ${ }^{15,34}$

Some case reports of "standard dose" amoxicillin treatment, failure have been reported in pneumococcal otitis media, particularly in cases with high-level penicillin resistance. ${ }^{19,34,49}$ However, it has been suggested that the administration of high doses of amoxicillin might be effective at least in those cases with intermediate penicillin resistance. ${ }^{19}$

Because in most cases microbiological cultures are not available, empirical antibiotic therapy should be selected to treat the most important microorganisms. It is important to know the prevalence of pneumococci resistant to penicillin and other antibiotics, as well as the prevalence of strains of $H$. influenzae and $M$. catarrhalis producing $\beta$-lactamase in the patient's geographic area.

As shown in Table 4, the treatment of choice for acute otitis media and acute sinusitis may be amoxicillin. In regions in which penicillin-resistant pneumococci is prevalent, the administration of high-dose amoxicillin may be prudent. In places with a high percentage of $H$. influenzaea and $M$. catarrhalis producing $\beta$-lactamase, amoxicillin-clavulanate or cefuroxime may be preferred.

Because of the low penetration of the antibiotics in the middle ear, otitis media caused by high-level penicillin-resistant pneumococci may not respond to standard doses of amoxicillin or amoxicilli-clavulanate. ${ }^{34}$ If a patient with acute otitis media has a clinical failure after $48 \mathrm{hr}$ of amoxicillin-clavulanate, amoxicillin at $30-40 \mathrm{mg} / \mathrm{kg}$ per day may be added to obtain higher amoxicillin dose (total $80 \mathrm{mg} / \mathrm{kg}$ per day) while not increasing the total clavulanate dose. ${ }^{19}$ Other alternative drugs (e.g., ceftriaxone, macrolide, or TMP-SMZ) may also be considered. Tympanocentesis may be required in patients who do not respond to therapy and this technique would allow the identification of the causative organism and susceptibility studies.

\section{ACKNOWLEDGMENT}

This paper was supported by a grant FIS 97-0716 from the National Health Service, Madrid.

\section{REFERENCES}

1. Abronheim, G.A., B. Reich, and M.I. Marks. 1979. Penicillininsensitive pneumococci. Am. J. Dis. Child. 133:187-191.

2. Almirante, B., E. Cortes, C. Pigrau, O. del Valle, I. Gasser, and A. Pahissa. 1995. Personal communication.

3. Alonso, J., V. Madrigal, and M. Garcia-Fuentes. 1991. Recurrent meningitis from a multiply resistant Streptococcus pneumoniae strain treated with erythromycin. Pediatr. Infect. Dis. J. 10:256.

4. Amsden, G.W., and J.J. Schentag. 1995. Tables of antimicrobial agent pharmacology, pp. 492-528. In G.L. Mandell, J.E. Bennet, and R. Dolin (ed.). Principles and Practice of Infectious Diseases, Fourth edition. Churchill Livingstone, New York.

5. Appelbaum, P.C. 1996. Epidemiology and in vitro susceptibility 
of drug-resistant Streptococcus pneumoniae. Pediatr. Infect. Dis. J. 15:932-939.

6. Appelbaum, P.C., A. Bhamjee, J.N. Scragg, A.J. Hallett, A.F. Bowen, and R.C. Cooper. 1977. Streptococcus pneumoniae resistant to penicillin and chloramphenicol. Lancet ii:995-997.

7. Arason, V.A., K.G. Kristinsson, J.A. Sigurdsson, G. Stefansdottir, S. Mölstad, and S. Gudmundsson. 1996. Do antimicrobials increase the carriage rate of penicillin-resistant pneumococci in children? Cross sectional prevalence study. Br. Med. J. 313: 387-391.

8. Asensi, F., M.C. Otero, D. Perez-Tamarit, I. Rodriguez-Escribano, J.L. Cabedo, S. Gresa, and E. Canton. 1993. Risk/benefit in the treatment of children with imipenem-cilastatin for meningitis caused by penicillin-resistant pneumococcus. J. Chemother. 5:133-134.

9. Asensi, F., D. Perez-Tamarit, M.C. Otero, M. Gallego, S. Llanes, C. Abadia, and E. Canton. 1989. Imipenem-cilastatin therapy in a child with meningitis caused by a multiply resistant pneumococcus. Pediatr. Infect. Dis. J. 8:895.

10. Austrian, R. 1994. Pneumococcal infections, pp. 607-611. In K.J. Isselbacher, E. Braunwald, J.D. Wilson, J.B. Martin, A.S. Fauci, and D.L. Kasper (ed.). Harrison's Principles of Internal Medicine, Thirteenth Edition. McGraw-Hill, Inc., New York.

11. Austrian, R. 1994. Confronting drug-resistant pneumolocci. Ann. Intern. Med. 121:807-809.

12. Baquero, F. 1995. Pneumococcal resistance to beta-lactam antibiotics: A global geographic overview. Microb. Drug Resist. 1:115120.

13. Baquero, F. 1996. Trends in antibiotic resistance of respiratory pathogens: An analysis and commentary on a collaborative surveillance study. J. Antimicrob. Chemother. 38(Suppl. A): 117-132.

14. Baquero, F., J. Martinez-Beltran, and E. Loza. 1991. A review of antibiotic resistance patterns of Streptococcus pneumoniae in Europe. J. Antimicrob. Chemother. 28(Suppl. C):31-38.

15. Berman, S. 1995. Otitis media in children. N. Engl. J. Med. 332:1560-1565.

16. Boken, D.J., S.A. Chartrand, R.V. Goering, R. Kruger, and C.H. Harrison. 1995. Colonization with penicillin-resistant Streptococcus pneumoniae in a child-care center. Pediatr. Infect. Dis. J. 14:879-884.

17. Bouza, E., and P. Muñoz. 1995. Penicillin-resistant pneumococci in adult disease with special reference to AIDS patients. Microb. Drug Resist. 1:9-28.

18. Bradley, J.S., and J.D. Connor. 1991. Ceftriaxone failure in meningitis caused by Streptococcus pneumoniae with reduced susceptibility to betalactam antibiotics. Pediatr. Infect. Dis. J. 10: 871-873.

19. Bradley, J.S., S.L. Kaplan, K.P. Klugman, and R.J. Leggiadro. 1995. Consensus: Management of infections in children caused by Streptococcus pneumoniae with decreased susceptibility to penicillin. Pediatr. Infect. Dis. J. 14:1037-1041.

20. Breiman, R.F., J.C. Butler, F.C. Tenover, J.A. Elliott, and R.R. Facklam. 1994. Emergence of drug-resistant pneumococcal infections in the United States. J. Am. Med. Assn. 271:1831-1835.

21. Caputo, G.M., P.C. Appelbaum, and H.H. Liu. 1993. Infections due to penicillin-resistant pneumococci: clinical, epidemiologic, and microbiologic features. Arch. Intern. Med. 153:1301-1310.

22. Caputo, G.M., F.R. Sattler, M.R. Jacobs, and P.C. Appelbaum. 1983. Penicillin-resistant pneumococcus and meningitis. Ann. Intern. Med. 98:416-417.

23. Catalan, M.J., J.M. Fernandez, A. Vazquez, E. Varela de Seijas, A. Suarez, and J.C.L. Bernaldo de Quiros. 1994. Failure of cefotaxime in the treatment of meningitis due to relatively resistant Streptococcus pneumoniae. Clin. Infect. Dis. 18:766769.

24. Collignon, P.J., J. Bell, I.W. Hufton, and D. Mitchell. 1988.
Meningitis caused by a penicillin- and chloramphenicol-resistant Streptococcus pneumoniae. Med. J. Aust. 149:497-498.

25. Dagan, R., L. Velghe, J.L. Rodda, and K.P. Klugman. 1994. Penetration of meropenem into the cerebrospinal fluid of patients with inflamed meninges. J. Antimicrob. Chemother. 34:175-179.

26. Del Castillo, F., A. Garcia-Perea, and F. Baquero-Artigao. 1996. Bacteriology of acute otitis media in Spain: A prospective study based on tympanocentesis. Pediatr. Infect. Dis. J. 15: 541-543.

27. Devitt, L., I. Riley, and D. Hansman. 1977. Human infection caused by penicillin-insensitive pneumococci. Med. J. Aust. 1:586-588.

28. Eriksen, K.R. 1945. Studies on induced resistance to penicillin in a pneumococcus type 1. Acta Pathol. Microbiol. Scand. 22: $398-405$.

29. Felmingham, D., R.N. Grüneberg, and the Alexander Project Group. 1996. A multicentre collaborative study of the antimicrobial susceptibility of community-acquired, lower respiratory tract pathogens 1992-1993: The Alexander Project. J. Antimicrob. Chemother. 38(Suppl. A):1-57.

30. Fenoll, A., C. Martin Bourgon, R. Muñoz, D. Vicioso, and J. Casal. 1991. Serotype distribution and antimicrobial resistance of Streptococcus pneumoniae isolates causing systemic infections in Spain, 1979-1989. Rev. Infect. Dis. 13:56-60.

31. Friedland, I.R. 1995. Comparison of the response to antimicrobial therapy of penicillin-resistant and penicillin-susceptible pneumococcal disease. Pediatr. Infect. Dis. J. 14:885-890.

32. Friedland, I.R., and Klugman, K.P. 1992. Failure of chloramphenicol therapy in penicillin-resistant pneumococcal meningitis. Lancet 339:405-408.

33. Friedland, I.R., and K.P. Klugman. 1992. Antibiotic-resistant pneumococci disease in South African children. Am. J. Dis. Child. 146:920-923.

34. Friedland, I.R., and G.H. McCracken, Jr. 1994. Management of infections caused by antibiotic-resistant Streptococcus pneumoniae. N. Engl. J. Med. 331:377-382.

35. Friedland, I.R., M. Paris, S. Ehrett, S. Hickey, K. Olsen, and G.H. McCracken, Jr. 1993. Evaluation of antimicrobial regimens for treatment of experimental penicillin- and cephalosporin-resistant pneumococcal meningitis. Antimicrob. Agents Chemother. 37:1630-1636.

36. Friedland, I.R., S. Shelton, M. Paris, S. Rinderknecht, S. Ehrett, K. Krisher, and G.H. McCracken, Jr. 1993. Dilemmas in diagnosis and management of cephalosporin-resistant Streptococcus pneumonaie meningitis. Pediatr. Infect. Dis. J. 12:196-200.

37. Garcia-Leoni, M.E., E. Cercenado, P. Rodeño, J.C.L. Bernaldo de Quiros, D. Martinez-Hernandez, and E. Bouza. 1992; Susceptibility of Streptococcus pneumoniae to penicillin: a prospective microbiological and clinical study. Clin. Infect. Dis. 14:427-435.

38. Gartner, J.C., and R.H. Michaels. 1979. Meningitis from a pneumococcus moderately resistant to penicillin. J. Am. Med. Assn. 241:1707-1709.

39. Gold, H.S., and R.C. Moellering, Jr. 1996. Antimicrobial-drug resistance. N. Engl. J. Med. 335:1445-1453.

40. Gwaltney, J.M. Jr. 1995. Sinusitis, pp. 585-90. In G.L. Mandell, J.E. Bennett, and R. Dolin (ed.). Principles and Practice of Infectious Diseases, 4th Edition. Churchill Livingstone, New York.

41. Hansman, D., L. Devitt, H. Miles, and I. Riley. 1974. Pneumococci relatively insensitive to penicillin in Australia and New Guinea. Med. J. Australia 2:353-356.

42. Hansman, D., H. Glasgow, J. Surt, H.L. Devitt, and R. Douglas. 1971. Increased resistance to penicillin of pneumococci isolated from man. N. Eng1. J. Med. 284:175-177.

43. Hieber, J.P., and J.D. Nelson. 1977. A pharmacologic evaluation 
of penicillin in children with purulent meningitis. N. Engl. J. Med. 297:410-413.

44. Hoberman, A. J.L. Paradise, S. Block, D.J. Burch, M.R. Jacobs, and M.I. Balanescu. 1996. Efficacy of amoxicillin/clavulanate for acute otitis media: relation to Streptococcus pneumoniae susceptibility. Pediatr. Infect. Dis. J. 15:955-962.

45. Hofmann, J., M.S. Cetron, M.M. Farley, W.S. Baughman, R.R. Facklan, J.A. Elliott, K.A. Deaver, and R.F. Breiman. 1995. The prevalence of drug-resistant Streptococcus pneumoniae in Atlanta. N. Engl. J. Med. 333:481-486.

46. Howes, V.J., and R.G. Mitchell. 1976. Meningitis due to relatively penicillin-resistant pneumococcus. Br. Med. J. 1:996.

47. Iyer, P.V., J.H. Kahler, and N.M. Jacobs. 1978. Penicillin-resistant pneumococcal meningitis. Pediatrics 61:157-158.

48. Jabes, D., S. Nachman, and A. Tomasz. 1989. Penicillin-binding protein families: evidence for the clonal nature of penicillin resistance in clinical isolates of pneumococci. J. Infect. Dis. 159:16-25.

49. Jacobs, M.R. 1996. Increasing importance of antibiotic-resistant Streptococcus pneumoniae in acute otitis media. Pediatr. Infect. Dis. J. 15:940-943.

50. Jacobs, M.R., H.J. Koornhof, R.M. Robins-Browne, R.M. Stevenson, Z.A. Vermaak, I. Freiman, G.B. Miller, M.A. Whitcomb, M. Isaacson, J.I. Ward, and R. Austrian. 1978. Emergence of multiply-resistant pneumococci. N. Engl. J. Med. 299: 735-740.

51. John, C.C. 1994. Treatment failure with use of a third-generation cephalosporin for penicillin-resistant pneumococcal meningitis: Case report and review. Clin. Infect. Dis. 18:188-193.

52. Kislak, J.W., L.M.B. Razavi, A.K. Daly, and M. Finland. 1965. Susceptibility of pneumococci to nine antibiotics. Am. J. Med. Sci. 250:262-268.

53. Kleiman, M.B., G.A. Weinberg, J.K. Reynolds, and S.D. Allen. 1993. Meningitis with beta-lactam-resistant Streptococcus pneumoniae: The need for early repeat lumbar puncture. Pediatr. Infect. Dis. J. 12:782-783.

54. Klugman, K.P. 1990. Pneumococcal resistance to antibiotics. Clin. Microbiol. Rev. 3:171-196.

55. Klugman, K.P. 1996. The clinical relevance of in-vitro resistance to penicillin, ampicillin, amoxycillin and alternative agents, for the treatment of community-acquired pneumonia caused by Streptococcus pneumoniae, Haemophilus influenzae and Moraxella catarrhalis. J. Antimicrob. Chemother. 38(Suppl. A):133-140.

56. Klugman, K.P., I.R. Friedland, and J.S. Bradley. 1995. Bactericidal activity against cephalosporin-resistant Streptococcus pneumoniae in cerebrospinal fluid of children with acute bacterial meningitis. Antimicrob. Agents Chemother. 39:1988-1992.

57. Latorre, C., T. Juncosa, and I. Santfeliu. 1985. Antibiotic resistance and serotypes of 100 Streptococcus pneumoniae strains isolated in a children's hospital in Barcelona, Spain. Antimicrob. Agents Chemother. 28:357-359.

58. Leggiadro, R.J., F.F. Barrett, P.J. Chesney, I. Davis, and F.C. Tenover. 1994. Invasive pneumococci with high level penicillin and cephalosporin resistance at a mid-south children's hospital. Pediatr. Infect. Dis. J. 13:320-322.

59. Liñares, J., T. Alonso, J.L. Perez, J. Ayats, M.A. Dominguez, R. Pallares, and R. Martin. 1992. Decreased susceptibility of penicillin-resistant pneumococci to twenty-four beta-lactam antibiotics. J. Antimicrob. Chemother. 30:279-288.

60. Liñares, J., R. Pallares, T. Alonso, J.L. Perez, J. Ayats, F. Gudiol, P.F. Viladrich, and R. Martin. 1992. Trends in antimicrobial resistance of clinical isolates of Streptococcus pneumoniae in Bellvitge Hospital, Barcelona, Spain (1979-1990). Clin. Infect. Dis. 15:99-105.

61. Lister, P.D. 1995. Multiply-resistant pneumococcus: Therapeutic problems in the management of serious infections. Eur. J. Clin. Microbiol. Infect. Dis. 14(Suppl. 1):18-25.
62. Mace, J.W., D.S. Janik, R.L. Sauer, and J.J. Quilligan, Jr. 1977. Penicillin-resistant pneumococcal meningitis in an immunocompromised infant. J. Pediatr. 91:506-507.

63. Mannheimer, S.B., L.W. Riley, and R.B. Roberts. 1996. Association of penicillin-resistant pneumococci with residence in a pediatric chronic care facility. J. Infect. Dis. 174:513-519.

64. Markiewicz, Z., and A. Thomasz. 1989. Variation in penicillinbinding protein patterns of penicillin-resistant clinical isolates of pneumococci. J. Clin. Microbiol. 27:405-410.

65. Marton, A., M. Gulyas, R. Muñoz, and A. Tomasz. 1991. Extremely high incidence of antibiotic resistance in clinical isolates of Streptococcus pneumoniae in Hungary. J. Infect. Dis. 163: 542-548.

66. Mason, E.O., S.L. Kaplan, L.B. Lamberth, and J. Tillman. 1992. Increased rate of isolation of penicillin-resistant Streptococcus pneumoniae in a children's hospital and in vitro susceptibilities to antibiotics of potential therapeutic use. Antimicrob. Agents Chemother. 36:1703-1707.

67. Mason, E.O., L. Lamberth, R. Lichenstein, and S.L. Kaplan. 1995. Distribution of Streptococcus pneumoniae resistant to penicillin in the USA and in-vitro susceptibility to selected oral antibiotics. J. Antimicrob. Chemother. 36:1043-1048.

68. Moreno, S., M.E. Garcia-Leon, E. Cercenado, M.D. Diaz, J.C. Bernaldo de Quiros, and E. Bouza. 1995. Infections caused by erythromycin-resistant Streptococcus pneumoniae: Incidence, risk factors, and response to therapy in a prospective study. Clin. Infect. Dis. 20:1195-1200.

69. Muñoz, R., T.J. Coffey, M. Daniels, C.G. Dowson, G. Laible J. Casal, R. Hakenbeck, M. Jacobs, J.M. Musser, B.G. Spratt, and A. Tomasz. 1991. Intercontinental spread of a multiresistant clone of serotype 23F Streptococcus pneumoniae. J. Infect. Dis. 164:302-306.

70. Musher, D.M. 1995. Streptococcus pneumoniae, pp. 1811-1826 In G.L. Mandell, J.E. Bennett, and R. Dolin (ed.). Principles and Practice of Infectious Diseases, 4th Edition. Churchill Livingstone, New York.

71. Musher, D.M., and S.J. Spindel. 1996. Community-acquired pneumonia, pp. 102-124. In J.S. Remington, and M.N. Swartz (ed.). Current Clinical Topics in Infectious Diseases. McGraw-Hill Book Co., New York.

72. Naraqi, S., G.P. Kirkpatrick, and S. Kabins. 1974. Relapsing pneumococcal meningitis: isolation of an organism with decreased susceptibility to penicillin G. J. Pediatr. 85:671-672.

73. Nava, J.M., F. Bella, J. Garau, J. Lite, M.A. Morena, C. Marti, D. FontanaIs, B. Font, V. Pineda, S. Uriz, F. Deulofeu, A. Calderon, P. Duran, M. Grau, and A. Agudo. 1994. Predictive factors for invasive disease due to penicillin-resistant Streptococcus pneumoniae: A population-based study. Clin. Infect. Dis. 19:884-890.

74. Pallares, R., F. Gudiol, J. Liñares, J. Ariza, G. Rufi, L. Murgui, J. Dorca, and P.F. Viladrich. 1987. Rick factors and response to antibiotic therapy in adults with bacteremic pneumonia caused by penicillin-resistant pneumococci. N. Engl. J. Med. 317:18-22.

75. Pallares, R., J. Liñares, M. Vadillo, C. Cabellos, F. Manresa, P.F. Viladrich, R. Martin, and F. Gudiol. 1995. Resistance to penicillin and cephalosporin and mortality from severe pneumococcal pneumonia in Barcelona, Spain. N. Engl. J. Med. 333: $474-480$.

76. Pankuch, G.A., M.A. Visalli, M.R. Jacobs, and P.C. Appelbaum. 1995. Activities of oral and parenteral agents against penicillin-susceptible and -resistant pneumococci. Antimicrob. Agents Chemother. 39:1499-1504.

77. Paredes, A., L.H. Taber, M.D. Yow, D. Clark, and W. Nathan. 1976. Prolonged pneumococcal meningitis due to an organism with increased resistance to penicillin. Pediatrics 58:378-381.

78. Paris, M.M., O. Ramilo, and G.H. McCracken, Jr. 1995. Man- 
agement of meningitis caused by penicillin-resistant Streptococcus pneumoniae. Antimicrob. Agents Chemother. 39:2171-2175.

79. Ridgway, E.J., K.D. Allen, T.J. Neal, M. Lombard, and A. Rigby. 1992. Pencillin-resistant pneumococcal meningitis. Lancet 339:931.

80. Sanchez, C., R. Armengol, J. Lite, I. Mir, and J. Garau. 1992. Penicillin-resistant pneumococci and community-acquired pneumonia. Lancet 339:988.

81. Sloas, M.M., F.F. Barrett, P.J. Chesney, B.K. English, B.C. Hill, F.C. Tenover, and R.J. Leggiadro. 1992. Cephalosporin treatment failure in penicillin- and cephalosporin-resistant Streptococcus pneumoniae meningitis. Pediatr. Infect. Dis. J. 11:662-666.

82. Soares, S., K.G. Kristinsson, J.M. Musser, and A. Tomasz. 1993. Evidence for the introduction of a multiresistant clone of $6 \mathrm{~B}$ Streptococcus pneumoniae from Spain to Iceland in the late 1980s. J. Infect. Dis. 168:158-163.

83. Spangler, S.K., M.R. Jacobs, and P.C. Appelbaum. 1994. Susceptibilities of 177 penicillin-susceptible and -resistant pneumococci to FK 037, cefpirome, cefepime, ceftriaxone, cefotaxime, ceftazidime, imipenem, biapenem, meropenem and vancomycin. Antimicrob. Agents Chemother. 38:898-900.

84. Tan, T.Q., E.O. Mason, Jr., and S.L. Kaplan. 1992. Systemic infections due to Streptococcus pneumoniae relatively resistant to penicillin in a children's hospital: Clinical management and outcome. Pediatrics 90:928-933.

85. Tomasz, A. 1995. The pneumococcus at the gates. N. Engl. J. Med. 333:514-515.

86. Tomasz, A., and R. Munoz. 1995. Beta-lactam antibiotic resistance in gram-positive bacterial pathogens of the upper respiratory tract: A brief overview of mechanisms. Microb. Drug Resist. 1:103-109.
87. Tubau, F., C. Cabellos, and J. Liñares. 1996. Lack of correlation between in vitro and in vivo studies of combinations of rifampin plus vancomycin or beta-lactam antibiotics against Streptococcus pneumoniae. Antimicrob. Agents Chemother. 40: 1573-1574.

88. Viladrich, P.F., C. Cabellos, R. Pallares, F. Tubau, J. MartinezLacasa, J. Liñares, and F. Gudiol. 1996. High doses of cefotaxime in treatment of adult meningitis due to Streptococcus pneumoniae with decreased susceptibilities to broad-spectrum cephalosporins. Antimicrob. Agents Chemother. 40:218-220.

89. Viladrich, P.F., F. Gudiol, J. Liñares, R. Pallares, I. Sabate, G. Rufi, and J. Ariza. 1991. Evaluation of vancomycin for therapy of adult pneumococcal meningitis. Antimicrob. Agents Chemother. 35:2467-2472.

90. Viladrich, P.F., F. Gudiol, J. Liñares, G. Rufi, J. Ariza, and R. Pallares. 1988. Characteristics and antibiotic therapy of adult meningitis due to penicillin-resistant pneumococci. Am. J. Med. 84:839-846.

91. Ward, J. 1981. Antibiotic-resistant Streptococcus pneumoniae: clinical and epidemiologic aspects. Rev. Infect. Dis. 3:254-266.

92. Willett, L.D., H.C. Dillon, Jr., and B.M. Gray. 1985. Penicillinintermediate pneumococci in a children's hospital. Am. J. Dis. Child. 139:1054-1057.

Address reprint requests to:

Roman Pallares

Infectious Diseases Service Hospital Bellvitge 08907 L'Hospitalet Barcelona, Spain 
This article has been cited by:

1. Matthew W. Loranger, Stephanie M. Forget, Nicole E. McCormick, Raymond T. Syvitski, David L. Jakeman. 2013. Synthesis and Evaluation of 1-Rhamnose 1C-Phosphonates as Nucleotidylyltransferase Inhibitors. The Journal of Organic Chemistry 78:19, 9822-9833. [CrossRef]

2. N. Asmah, B. Eberspacher, T. Regnath, M. Arvand. 2009. Prevalence of erythromycin and clindamycin resistance among clinical isolates of the Streptococcus anginosus group in Germany. Journal of Medical Microbiology 58:2, 222-227. [CrossRef]

3. Wen C. CHIANG, Oon H. TEOH, Chia Y. CHONG, Anne GOH, Jenny P.L. TANG, Oh M. CHAY. 2007. Epidemiology, clinical characteristics and antimicrobial resistance patterns of community-acquired pneumonia in 1702 hospitalized children in Singapore. Respirology 12:2, 254-261. [CrossRef]

4. J.-P. Sollet, C. Legall. 2006. Neumonías comunitarias graves del adulto. EMC - Anestesia-Reanimación 32:1, 1-20. [CrossRef]

5. J.-P. Sollet, C. Legall. 2005. Pneumonies communautaires graves de l'adulte. EMC - Anesthésie-Réanimation 2:4, 1-18. [CrossRef]

6. Flavia Huygens, John F. O\&rsquo;Sullivan, Constance E.J. van Rensburg. 2005. Antimicrobial Activities of Seven Novel Tetramethylpiperidine-Substituted Phenazines against Multiple-Drug-Resistant Gram-Positive Bacteria. Chemotherapy 51:5, 263-267. [CrossRef]

7. K KLUGMAN, D LOW, J METLAY, J PECHERE, K WEISS. 2004. Community-acquired pneumonia: new management strategies for evolving pathogens and antimicrobial susceptibilities. International Journal of Antimicrobial Agents 24:5, 411-422. [CrossRef]

8. David Lieberman, Devora Lieberman. 2003. Management of respiratory infections in the elderly. Expert Review of Antiinfective Therapy 1:3, 505-516. [CrossRef]

9. Xavier Sáez-Llorens, George H McCracken. 2003. Bacterial meningitis in children. The Lancet 361:9375, 2139-2148. [CrossRef]

10. Javier Garau. 2002. Treatment of drug-resistant pneumococcal pneumonia. The Lancet Infectious Diseases 2:7, 404-415. [CrossRef]

11. Richard B. Roberts, Alexander Tomasz, Alejandra Corso, Judie Hargrave, Elena Severina. 2001. Penicillin-Resistant Streptococcus pneumoniae in Metropolitan New York Hospitals: Case Control Study and Molecular Typing of Resistant Isolates. Microbial Drug Resistance 7:2, 137-152. [Abstract] [Full Text PDF] [Full Text PDF with Links]

12. Beatriz Rosón, Jordi Carratalà, Fe Tubau, Jordi Dorca, Josefina Liñares, Roman Pallares, Frederic Manresa, Francesc Gudiol. 2001. Usefulness of Betalactam Therapy for Community-Acquired Pneumonia in the Era of Drug-Resistant Streptococcus pneumoniae: A Randomized Study of Amoxicillin-Clavulanate and Ceftriaxone. Microbial Drug Resistance 7:1, 85-96. [Abstract] [Full Text PDF] [Full Text PDF with Links]

13. L. A. Mandell, T. J. Marrie, R. F. Grossman, A. W. Chow, R. H. Hyland. 2000. Canadian Guidelines for the Initial Management of Community-Acquired Pneumonia: An Evidence-Based Update by the Canadian Infectious Diseases Society and the Canadian Thoracic Society. Clinical Infectious Diseases 31:2, 383-421. [CrossRef]

14. B.K. De, J.S. Sampson, E.W. Ades, R.C. Huebner, D.L. Jue, S.E. Johnson, M. Espina, A.R. Stinson, D.E. Briles, G.M. Carlone. 2000. Purification and characterization of Streptococcus pneumoniae palmitoylated pneumococcal surface adhesin A expressed in Escherichia coli. Vaccine 18:17, 1811-1821. [CrossRef]

15. Roman Pallares, Olga Capdevila, Immaculada Grau. 1999. Treatment options for resistant pneumococcal infections. Clinical Microbiology and Infection 5, S3-S11. [CrossRef] 